\title{
MATING SYSTEM AND FEMALE REPRODUCTIVE SUCCESS OF THE ENDEMIC, EPIPHYTIC PROSTHECHEA AFF. KARWINSKII (ORCHIDACEAE)
}

\author{
Erika CAmacho-Domínguez \& Irene Ávila- Díaz \\ Facultad de Biología, Universidad Michoacana de San Nicolás de Hidalgo, Edificio R \\ planta baja, Ciudad Universitaria, 58040 Morelia, Michoacán, México \\ *Corrersponding author: laakire@yahoo.com
}

Prosthechea aff. karwinskii (Mart.) Soto Arenas \& Salazar (unpublished name) is an endemic Mexican epiphytic orchid with a restricted distribution. It occurs in deciduous oak forests, particularly on Quercus deserticola in the northern portion of Michoacán state. Due to their ornamental uses, this and other orchid species have been heavily collected from their natural populations. Learning about the reproductive biology of this species is important, as we may gain knowledge about the probable repercussions of overcollecting on their genetics and ecology. This will be a useful tool for the management and conservation of the species. The objectives were to 1) study the mating system of $P$. aff. karwinskii, 2) determine if the species requires an external pollinating agent for sexual reproduction, and 3) evaluate female reproductive success of this species. Exclusions (150) were made before anthesis. Once the flowers opened, we applied four pollination treatments: manual selfing, outcrossing, spontaneous autogamy, and open pollination. We subsequently quantified the production of fruits and viability of the seeds. Preliminary results showed that outcrossing and selfing treatments exhibited statistically higher fruit set than spontaneous autogamy and open pollination treatments, meaning that $P$. aff. karwinskii has the capability to reproduce via self-pollination. Prosthechea aff. karwinskii is pollinator-dependent for sexual reproduction, taking into account that the spontaneous autogamy treatment showed nil fruit production. Female reproductive success in open pollinated flowers was lower compared to fruit set of hand pollination treatments. This indicates that this species, as other species of tropical orchids, is pollination-limited. 